Article

\title{
Exploitation and Utilization of Oilfield Geothermal Resources in China
}

\author{
Shejiao Wang ${ }^{1, *}$, Jiahong Yan ${ }^{1}$, Feng $\mathrm{Li}^{2}$, Junwen $\mathrm{Hu}^{1}$ and Kewen $\mathrm{Li}^{3}$ \\ 1 PetroChina Research Institute of Petroleum Exploration \& Development, Beijing 100083, China; \\ yanjiahong@petrochina.com.cn (J.Y.); hjwen@petrochina.com.cn (J.H.) \\ 2 PetroChina Research \& Development Department, Beijing 100007, China; lfe@petrochina.com.cn \\ 3 School of Energy Resources, China University of Geosciences (Beijing), Beijing 100083, China; \\ likewen1268@163.com \\ * Correspondence: wsj@petrochina.com.cn; Tel.: +86-10-8359-8479 \\ Academic Editor: Kamel Hooman \\ Received: 27 May 2016; Accepted: 19 September 2016; Published: 30 September 2016
}

\begin{abstract}
Geothermal energy is a clean, green renewable resource, which can be utilized for power generation, heating, cooling, and could effectively replace oil, gas, and coal. In recent years, oil companies have put more efforts into exploiting and utilizing geothermal energy with advanced technologies for heat-tracing oil gathering and transportation, central heating, etc., which has not only reduced resource waste, but also improved large-scale and industrial resource utilization levels, and has achieved remarkable economic and social benefits. Based on the analysis of oilfield geothermal energy development status, resource potential, and exploitation and utilization modes, the advantages and disadvantages of harnessing oilfield geothermal resource have been discussed. Oilfield geothermal energy exploitation and utilization have advantages in resources, technical personnel, technology, and a large number of abandoned wells that could be reconstructed and utilized. Due to the high heat demand in oilfields, geothermal energy exploitation and utilization can effectively replace oil, gas, coal, and other fossil fuels, and has bright prospects. The key factors limiting oilfield geothermal energy exploitation and utilization are also pointed out in this paper, including immature technologies, lack of overall planning, lack of standards in resource assessment, and economic assessment, lack of incentive policies, etc.
\end{abstract}

Keywords: geothermal resource; geothermal energy exploitation and utilization; oilfield geothermal energy; advantage-disadvantage analysis

\section{Introduction}

There are abundant medium and low-temperature geothermal resources in China, with the amount of total resources equivalent to $8532 \times 10^{8} \mathrm{t}$ of standard coal [1], which are mainly distributed in petroliferous basins. Many oilfields in eastern China have stepped into the mid-late development stage, with increasing water production and an average water-cut of above $90 \%$. In fact, the separated geothermal water is a valuable geothermal resource, and therefore, these oilfields can be considered as "water fields" rather than oilfields in the traditional sense [2].

During China's 12th Five-Year Plan period, oil companies increased their efforts put into geothermal energy exploitation, utilization, and development. Medium- and low-temperature geothermal power generation, heat-tracing oil gathering and transportation, geothermal heating, and other geothermal energy exploitation and utilization projects have been successively carried out in the Huabei Oilfield (Renqiu, China), Liaohe Oilfield (Panjin, China), Daqing Oilfield (Daqing, China), and Shengli Oilfield (Dongying, China), to replace part of the energy consumption of oil, gas, and coal in the oil companies, and have achieved good economic and social benefits [3]. A series of 
research efforts, including oilfield geothermal water reinjection technology, gas heat pump technology, medium and low-temperature geothermal power generation applications, oilfield geothermal resource assessment, etc., have been conducted and have made significant progress.

It is well known that oil companies are not only major energy producers but also large energy consumers; they consume a large amount of gas, oil, and coal in order to heat living spaces, perform thermal recovery of heavy oil, provide heating to oil pipelines, etc. This consumption of gas and oil not only increases operating costs, but also living costs. The exploitation and utilization of available oilfield thermal resources could not only replace oil, gas, coal, and other fossil fuels [4-8], but could also provide a new path for oilfield economic diversification and future development. Therefore, the exploitation and utilization of oilfield geothermal energy has a bright future.

\section{Relationship between Oilfield Geothermal Energy and Oil and Gas}

The geothermal energy, geothermal gradient, and heat flow all significantly increase from west to east in China (Figure 1), and geothermal resources in the east are also more abundant than those in the west. Songliao Basin, Bohai Bay Basin, and other basins in Eastern China are rift basins with thinner lithosphere, which had intensive tectonic movements in the Mesozoic-Cenozoic periods and now have well-developed basement faults. These basins not only have higher geothermal gradients but also have very abundant geothermal resources.

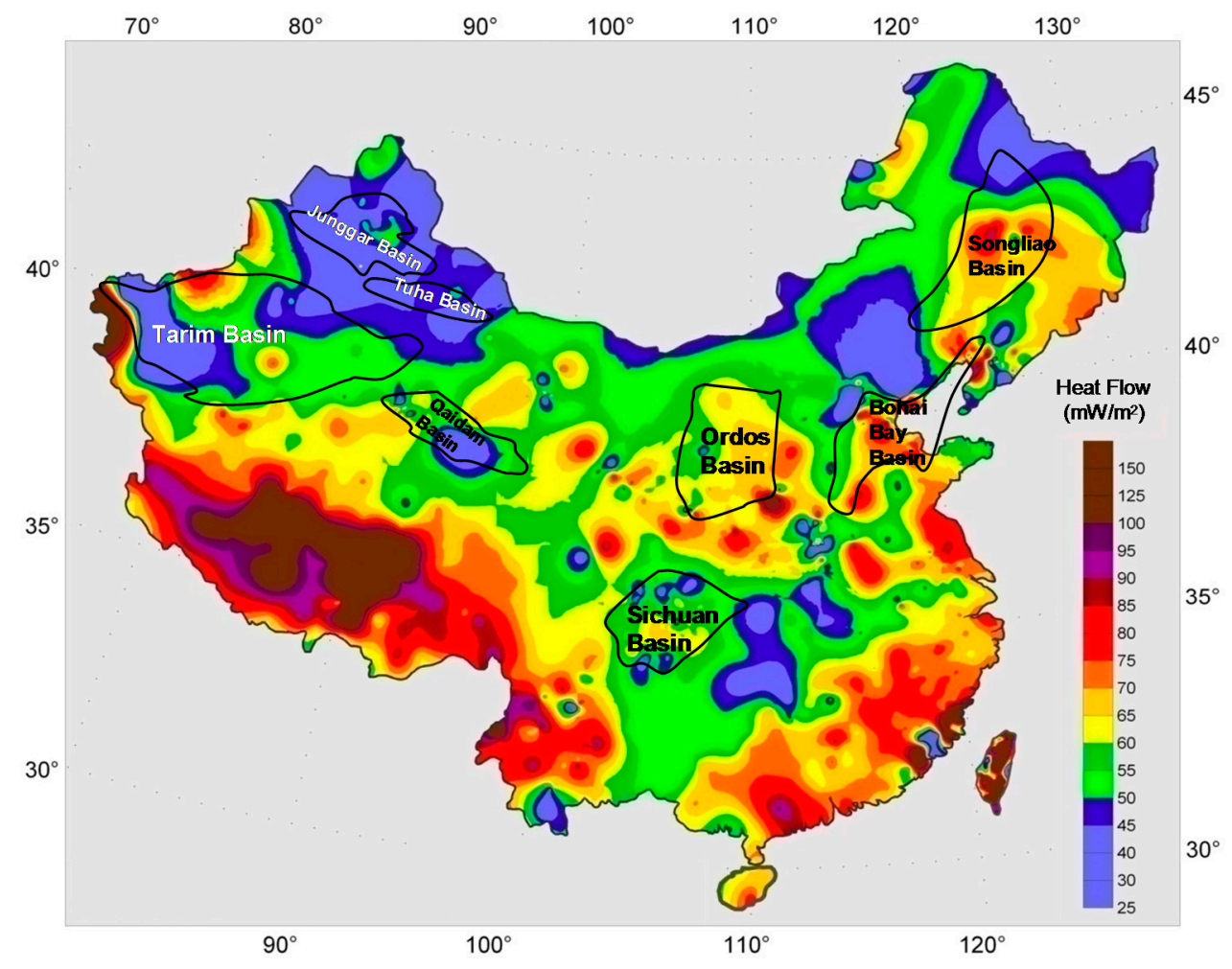

Figure 1. Distribution of petroliferous basins and heat flow in China [9].

Geothermal energy and oil are two kinds of resources that coexist in sedimentary basins. Oilfields in sedimentary basins are also abundant in geothermal resources, with abundant geothermal energy in their deepest regions. The hydrocarbon accumulation conditions are very similar to that of geothermal fields in hydrocarbon basins. Hydrocarbon is generated under a specific temperature, and groundwater is always involved both in the primary migration of oil expulsed by the source rock and in the secondary migration of oil and gas to the reservoir. Geothermal energy conduction and convection in the Earth's crust also have groundwater as a working fluid. Therefore, there is an interdependent relationship 
between groundwater, hydrocarbon, and geothermal energy. In petroliferous basins, hydrocarbon reservoirs are often also geothermal energy reservoirs, and similarly hydrocarbon fields are also often geothermal fields. Reservoirs with oil on top and water on the bottom, or interbedded oil and water layers correspond to coexisting hydrocarbon oilfields and geothermal fields, where the produced water is actually a geothermal resource. Generally, the geothermal reservoir volume and total resources are much larger than that of the hydrocarbon reservoir volume, and thus the total amount of geothermal resources is larger than the total amount of hydrocarbon resources in oilfields, with only the energy density of the geothermal resources being much lower than that of the hydrocarbon resources.

Studies show that Bohai Bay Basin and Songliao Basin are abundant in both hydrocarbon and medium- and low-temperature conductive geothermal resources. In recent years, oil companies have put more efforts into exploiting and utilizing geothermal resources, through the establishment of pilot projects in Huabei Oilfield, Daqing Oilfield, and Liaohe Oilfield [3,10], and have achieved satisfactory progress and valuable experience.

\section{Overview of Oilfield Geothermal Energy Exploitation and Utilization}

Taking the lead in geothermal energy exploitation and utilization, Sinopec (Beijing, China) has become the largest company of geothermal exploitation and utilization in China. Since 2011, Sinopec has made geothermal energy a separate business unit to improve overall planning, the Sinopec Star Petroleum Co., Ltd. (Beijing, China) has been positioned as a specialized clean energy company, the Geothermal Research Institute has been set up to carry out basic research and technology development, and the "National Geothermal Energy Exploitation \& Utilization Research and Application Technology Promotion Center" has also been set up in Sinopec. At present, Sinopec's geothermal business has entered a new stage spanning the whole country. By the end of 2014, Sinopec geothermal space heating using moderate formation depths (200-3000 m) reached $40 \times 10^{6} \mathrm{~m}^{2}$, accounting for $40 \%$ of the total geothermal heating area in China, which replaced $1.2 \times 10^{6} \mathrm{t}$ of standard coal per year and reduced $3 \times 10^{6} \mathrm{t}$ of carbon dioxide emission per year.

"Xiong County Mode" has become a model of oilfield geothermal energy utilization. Located in Baoding City of the Hebei Province, Xiong County is an exploration area of PetroChina Huabei Oilfield, where the geothermal reservoir is the Wumishan Formation, main carbonate rock, in the Niutuo Town geothermal field; at an exploitation depth of 1600-1700 m, and a wellhead temperature of $60-70{ }^{\circ} \mathrm{C}$, the geothermal resource features easy reinjection, high temperature, and large water quantity. An extraction-reinjection combination (one-extraction and one-reinjection well) has been realized in geothermal energy exploitation in this area.

"Xiong County Mode" is a geothermal energy exploitation project jointly implemented by Sinopec Star Petroleum Co., Ltd. (Beijing, China) and the Baoding government. "Heat-utilization without water consumption" technology is utilized by the project, in which the spent water is reinjected underground after utilizing the geothermal energy from the water. With a geothermal heating area of $3.28 \times 10^{6} \mathrm{~m}^{2}$, and $100 \%$ urban geothermal heating, the area has become a smoke-free area during the winter heating season, and has drawn considerable attention across China. The National Energy Administration is promoting the Xiong County geothermal heating mode energetically.

A geothermal heating project in this area is taken as an example to analyze the economics of geothermal energy exploitation and utilization in the following section. The geothermal heating project plans to deploy 48 geothermal wells, including 27 producing wells and 21 reinjection wells, construct 9 geothermal stations, and the corresponding heat pipe network. The project has a total heating area of $1.7 \times 10^{6} \mathrm{~m}^{2}$, a construction period of 3 years, and an operational period of 12 years. The project investment is $¥ 209,280,000$, including the ground construction and drilling engineering cost. Economic evaluation shows that the project has a NPV (Net Present Value) of $¥ 18,620,000$, an internal rate of return of $14 \%$, and a payback period of 8 years (Figures 2 and 3), indicating a good economic return.

A number of geothermal energy utilization projects (Table 1) have also been carried out in PetroChina Daqing Oilfield, Huabei Oilfield, Liaohe Oilfield, etc. Five geothermal energy utilization 
projects utilizing the waste-heat of produced water have been implemented in the Daqing Oilfield to supply heat for living quarters and oil gathering and transportation, which can replace $7000 \mathrm{t}$ of standard coal per year. Twelve geothermal energy utilization projects have been implemented in the Liaohe Oilfield for building heating, which replaced 24,400 $t$ of standard coal per year. Five geothermal energy utilization projects have been implemented in the Huabei Oilfield, which can save $180,000 \mathrm{~m}^{3}$ of gas, $6800 \mathrm{t}$ of oil, and $600 \mathrm{t}$ of coal per year. In addition, Huabei Oilfield has also started a $400 \mathrm{~kW}$ medium and low-temperature geothermal power generation pilot project [3].
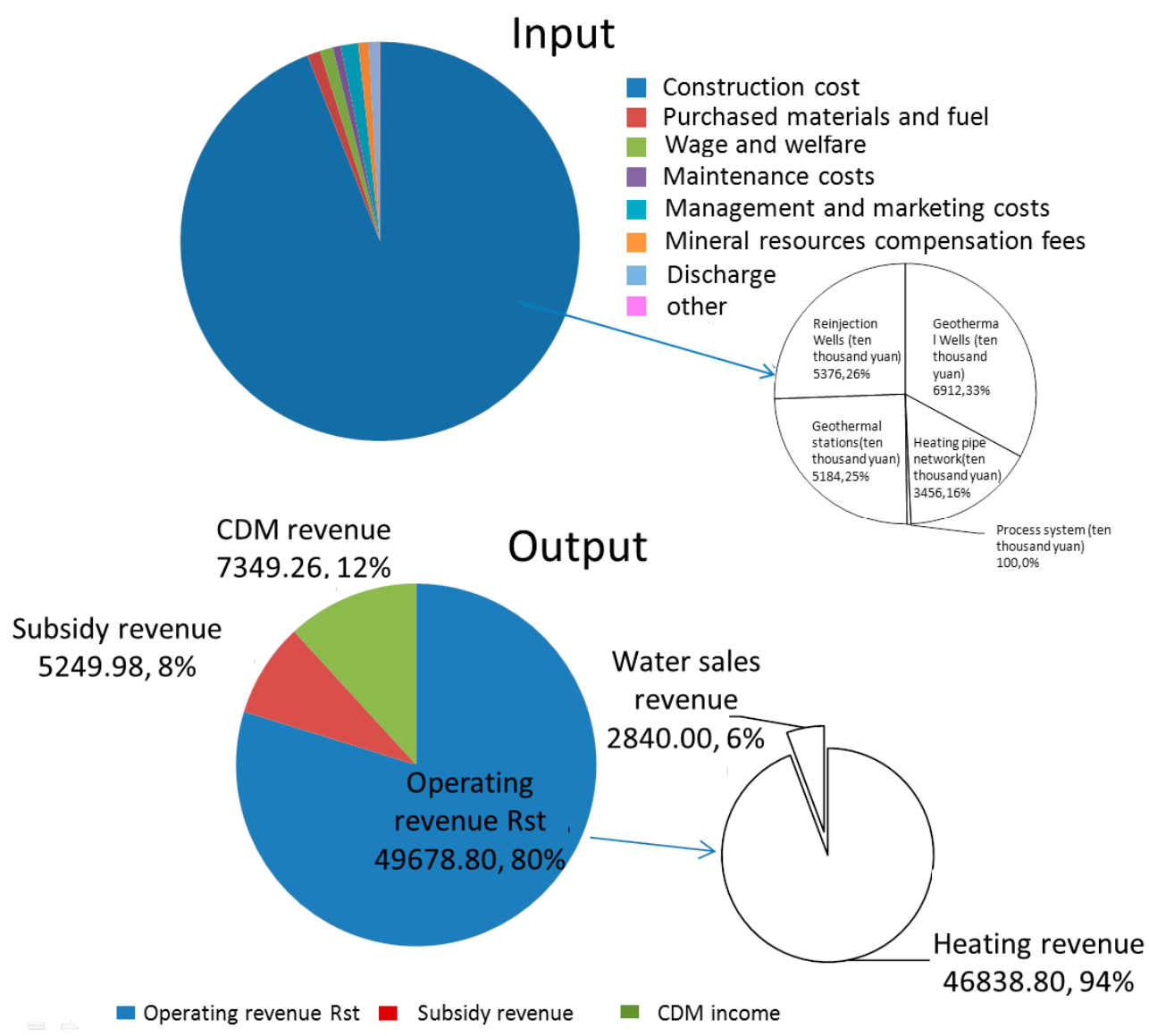

Figure 2. Geothermal project input and output.

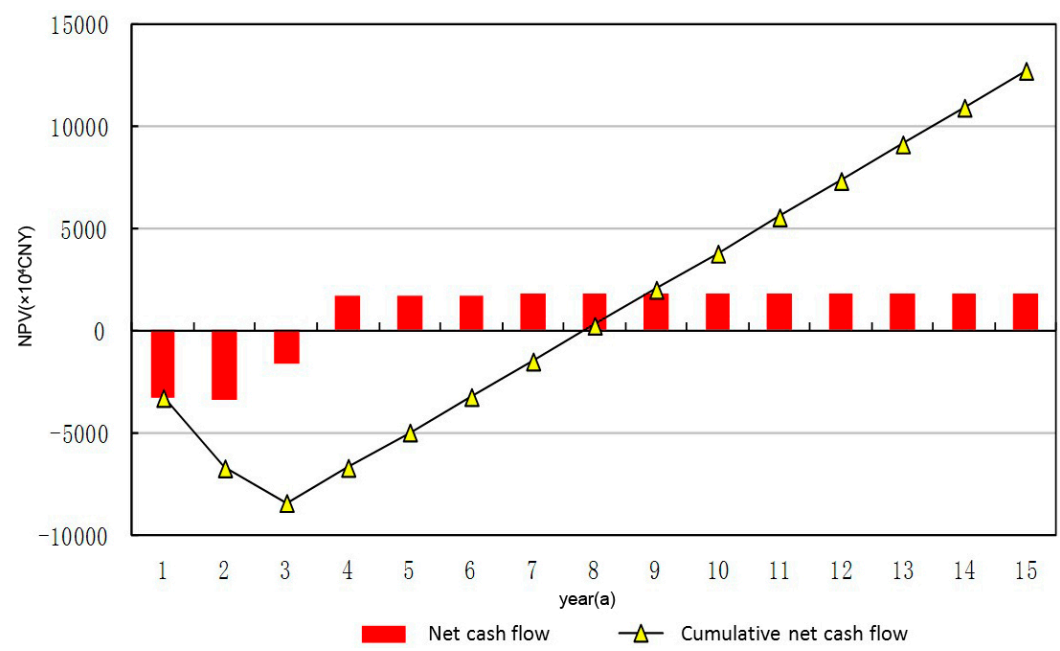

Figure 3. Geothermal project cash flow. 
Table 1. Geothermal energy utilization projects in oilfields.

\begin{tabular}{|c|c|c|c|c|}
\hline Oilfield & Daqing & Liaohe & Huabei & Zhongyuan \\
\hline $\begin{array}{l}\text { Number of } \\
\text { Projects }\end{array}$ & 5 & 12 & 5 & 1 \\
\hline $\begin{array}{l}\text { Geothermal } \\
\text { Source }\end{array}$ & $\begin{array}{l}\text { Waste-heat } \\
\text { utilization of } \\
\text { produced water }\end{array}$ & $\begin{array}{l}\text { Waste-heat utilization of } \\
\text { produced water, drilling } \\
\text { geothermal well }\end{array}$ & $\begin{array}{l}\text { Waste-heat utilization of } \\
\text { produced water, } \\
\text { reconstructing abandoned } \\
\text { wells to geothermal wells }\end{array}$ & $\begin{array}{l}\text { Waste-heat } \\
\text { utilization of } \\
\text { produced water }\end{array}$ \\
\hline Technology & Heat pump & Heat pump & $\begin{array}{l}\text { Direct utilization medium } \\
\text { and Low-temperature } \\
\text { geothermal power } \\
\text { generation }\end{array}$ & Heat pump \\
\hline $\begin{array}{c}\text { Major } \\
\text { Application }\end{array}$ & $\begin{array}{l}\text { Space heating, } \\
\text { heat-tracing oil } \\
\text { gathering and } \\
\text { transportation }\end{array}$ & Space heating, bathing & $\begin{array}{l}\text { Heat-tracing oil gathering } \\
\text { and transportation, power } \\
\text { generation }\end{array}$ & Space heating \\
\hline Efficiency & $\begin{array}{l}\text { Replace } 7000 \mathrm{t} \text { of } \\
\text { standard coal } \\
\text { per year }\end{array}$ & $\begin{array}{l}\text { Replace } 24,400 t \text { of } \\
\text { standard coal per year }\end{array}$ & $\begin{array}{l}\text { Save } 180,000 \mathrm{~m}^{3} \text { of gas, } \\
6800 \mathrm{t} \text { of oil and } 600 \mathrm{t} \text { of coal } \\
\text { per year }\end{array}$ & $\begin{array}{l}\text { Save } 2537 \mathrm{t} \text { of } \\
\text { standard coal } \\
\text { per year }\end{array}$ \\
\hline
\end{tabular}

\section{Advantages and Disadvantages of Oilfield Geothermal Energy Exploitation and Utilization}

\subsection{Advantages in Oilfield Geothermal Energy Exploitation and Utilization}

\subsubsection{Abundant Geothermal Resources in Oilfields}

The distribution of geothermal water resources has been determined at the same time as hydrocarbon exploration and development in petroliferous basins.

Produced water in an oilfield is a geothermal resource taken out during hydrocarbon development. Oilfield produced water, also known as oilfield produced waste water or oilfield sewage, is water that is produced with oil from production wells. Hydrocarbon reservoirs are generally located in the earth's crust, with temperatures increasing at great burial depths, where heat conduction leads to relatively high formation temperatures. Moving with the oil, the water in oilfields stores a lot of heat. The temperature of oilfield produced water is usually above $40{ }^{\circ} \mathrm{C}$, representing a wealth of thermal energy. The geothermal energy of oilfield produced water can be classified as a medium and low-temperature geothermal resource according to the geothermal resource concept and classification, a sedimentary basin geothermal resource according to geological structure properties, and a hydrothermal geothermal resource according to its carrier. In contrast, the carrier of a geothermal resource in oilfield produced water is a water-oil-gas mixture, which mainly consists of oilfield injected water. Therefore, this type of geothermal resource being carried by oilfield produced water can be defined as an oilfield produced water geothermal resource, a special medium and low-temperature hydrothermal geothermal resource in sedimentary basins [11-14].

Hydrocarbon exploration and development demonstrates that sedimentary basins are not only rich in hydrocarbon resources, but also medium- and low-temperature geothermal resources. The latest geothermal resource assessment of major petroliferous basins (Table 2, Figure 4) reveals that in the most resource-rich basins, Bohai Bay Basin and Songliao Basin, the total geothermal resources in Daqing Oilfield, Liaohe Oilfield, and Huabei Oilfield are up to $11,012 \times 10^{18} \mathrm{~J}$, and recoverable geothermal resources are up to $424 \times 10^{18} \mathrm{~J}$, equivalent to $3757 \times 10^{8} \mathrm{t}$ and $145 \times 10^{8} \mathrm{t}$ of standard coal, respectively [15]. 
Table 2. Geothermal resource assessment of three oilfields.

\begin{tabular}{cccccc}
\hline \multirow{2}{*}{ Oilfield } & Area $\left.\mathbf{( k m}^{\mathbf{2}}\right)$ & \multicolumn{2}{c}{ Geological Resource } & \multicolumn{2}{c}{ Recoverable Resource } \\
\cline { 3 - 6 } & & $\begin{array}{c}\text { Thermal Energy } \\
\left(\times \mathbf{1 0}^{\mathbf{1 8}} \mathbf{~}\right)\end{array}$ & $\begin{array}{c}\text { Water Volume } \\
\left(\times \mathbf{1 0}^{\mathbf{8}} \mathbf{~ m}^{\mathbf{3}}\right)\end{array}$ & $\begin{array}{c}\text { Water Volume } \\
\left(\times \mathbf{1 0}^{\mathbf{8}} \mathbf{~ m}^{\mathbf{3}}\right)\end{array}$ & $\begin{array}{c}\text { Thermal Energy } \\
\left(\times \mathbf{1 0}^{\mathbf{1 8}} \mathbf{~} \mathbf{)}\right.\end{array}$ \\
\hline Huabei & 32,000 & 7099 & 53,727 & 11,399 & 306 \\
Daqing & 120,000 & 2905 & 24,400 & 6090 & 89 \\
Liaohe & 25,000 & 1008 & 8529 & 1832 & 29 \\
Total & & 11,012 & 86,656 & 19,321 & 424 \\
\hline
\end{tabular}

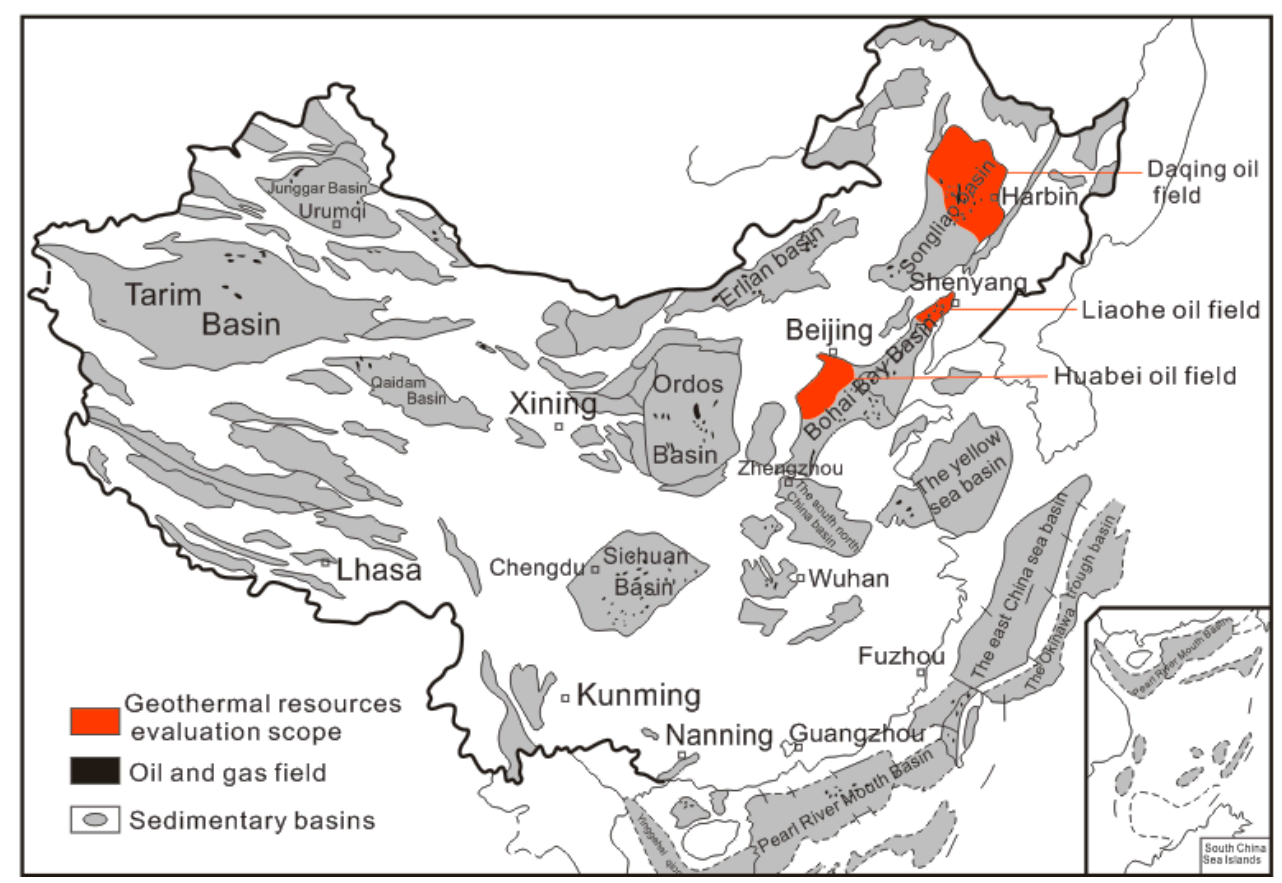

Figure 4. Major hydrocarbon basins and geothermal resource assessment scope.

The calculation of geothermal resources is based on the volumetric method, and the calculation formulas are [16]:

$$
\begin{gathered}
Q_{R}=A \cdot d \cdot\left(t_{r}-t_{j}\right) \cdot \bar{C} \\
\bar{C}=\rho_{c} \cdot C_{c} \cdot(1-\Phi)+\rho_{w} \cdot C_{w} \cdot \Phi
\end{gathered}
$$

where, $A$-block area, $\mathrm{m}^{2} ; d$-average thickness of the block, $\mathrm{m} ; \Phi$-average porosity of the reservoir, $\% ; t_{r}$-reservoir temperature, ${ }^{\circ} \mathrm{C} ; t_{j}$-temperature of normal temperature zone, ${ }^{\circ} \mathrm{C} ; \rho_{c}$-density of reservoir rock, $\mathrm{kg} / \mathrm{m}^{3} ; C_{c}$-specific heat of reservoir rock, $\mathrm{J} /\left(\mathrm{kg} \cdot{ }^{\circ} \mathrm{C}\right) ; \rho_{w}$-density of formation water, $\mathrm{kg} / \mathrm{m}^{3} ; C_{w}$-specific heat of formation water, $\mathrm{J} /\left(\mathrm{kg} \cdot{ }^{\circ} \mathrm{C}\right)$.

Recoverable resources include recoverable water volume and recoverable thermal energy. Recoverable thermal energy comes from recoverable water, not from geological thermal energy.

The recovery factor is quite variable from resource to resource and is difficult to define. Rock properties, geological conditions, the level of the local economy, and demand should be considered. In this paper, we used empirical values obtained in China. The recoverable coefficient of layered pore type reservoir is taken as $0.2-0.3$ and for crack type reservoir the value is taken as $0.05-0.1$. These recoverable coefficients differ from those reported by Williams et al., who list values of 0.1 to 0.25 for sediment-hosted reservoirs and 0.08 to 0.2 for fracture-dominated reservoirs [17]. 
4.1.2. Oilfield Companies Are Both Major Energy Producers and Consumers, and Geothermal Energy Can Replace Oil, Gas, Coal, and Other Fossil Fuels

It is well known that oilfields are both major energy producers and consumers, and a large amount of gas, oil, and coal are consumed for heating living spaces, thermal recovery of heavy oil, oil gathering and transportation, etc., each year. Many processing measures consume a lot of heat in the oil production process; for example, heating is required for crude oil dehydration and transportation, and especially heavy oil, with higher viscosity, must be heated to reduce its viscosity before pipeline transportation.

According to incomplete statistics, the annual energy consumption of oilfield furnaces and boilers is at least $1.0 \times 10^{6} \mathrm{t}$ of crude oil and $30 \times 10^{8} \mathrm{~m}^{3}$ of gas. The consumption of gas and oil not only increase the operating costs, but also the living costs. The exploitation and utilization of available oilfield geothermal resources cannot only replace oil, gas, coal, and other fossil fuels, but can also provide a new path for oilfield economic diversification and future development.

In addition, the annual oilfield produced water volume exceeds $7 \times 10^{8} \mathrm{~m}^{3}$, which contains rich medium and low-temperature geothermal energy that can be directly utilized. According to the calculation of extracting 10 degrees celsius thermal energy (heat pump), the available thermal energy is equivalent to about $1.3 \times 10^{6} \mathrm{t}$ of standard coal and also equivalent to an oilfield with an annual oil production of $0.9 \times 10^{6} \mathrm{t}$; which is a quite considerable amount of heat.

\subsubsection{Abundance of Geological Data and Abandoned Wells in Oilfield}

In the oilfield geothermal study, the geological data mainly came from data of the exploration and development wells in the oilfields, and those wells reached thousands in number. A wealth of geological, geophysical, geochemical, logging, production data, and other basic data have been accumulated during the exploration and development of hydrocarbon fields and many databases have been established, which can provide a valuable database for oilfield geothermal energy exploitation and reduce the costs and risks of oilfield geothermal energy exploitation and utilization.

In addition, there are a large number of abandoned wells that were constructed during oilfield exploration and development, and many abandoned wells with intact wellbore structures and considerable economic value can be realized if these wells are recompleted for geothermal energy production. Geothermal energy exploitation through the use of abandoned wells will not only activate oilfield sunken assets, but also reduce the initial investment [18,19]. For example, two abandoned wells in the Jing'er multipurpose station of the Huabei Oilfield have been reconstructed to produce geothermal water for heat-tracing gathering and transportation, which can save about $5 \mathrm{t}$ of oil and $3.5 \times 10^{3} \mathrm{~m}^{3}$ of gas every day. A preliminary survey of abandoned wells in the Daqing and Liaohe Oilfields indicates that the number of available wells for geothermal energy exploitation exceeds 6000 . These abandoned wells in different areas have different wellhead fluid temperatures ranging from $50^{\circ} \mathrm{C}$ to $110{ }^{\circ} \mathrm{C}$, and fluid productions of several hundreds of cubic meters. At present, wells used for geothermal exploitation are very limited in number. No well is currently being used to exploit geothermal energy while producing oil and gas.

The oil and gas wells reconstructed as geothermal development wells would need to be worked over, which can save $2 / 3$ of the cost of drilling geothermal development wells directly. Currently, as the geothermal exploitation projects in China's oilfields are very small in scale, the surface facilities mainly rely on preexisting ones. In the central heating project, the heated area is taken out of the oilfield mining area. The geothermal water is then reinjected back into the formation completely; taking Xiong County in the Huabei oilfield as an example, the geothermal reservoir is the Wumishan Formation carbonate, where the spent water after geothermal exploitation has all been reinjected, with satisfactory effect.

In general, the reconstruction and utilization of these abandoned wells can not only lower geothermal energy exploitation costs, but can also effectively reduce exploitation risk. However, these abandoned wells have such issues as unclear management responsibility, wellhead damage, or external 
occupation, so oil companies will need to implement systematic management, assess their present value, and work out property transfer modes.

\subsubsection{Engineering Technology Advantages in Oilfields}

Oilfield drilling, testing, hot water transportation, water treatment, surface engineering, and other conventional technologies are also applicable to geothermal energy exploitation, and oilfield personnel, technology, and equipment also provide very convenient conversion conditions for geothermal energy exploitation. Geothermal energy exploitation practices show that the geological data of hydrocarbon exploration can be used to assess the geothermal resources. Oil and gas wellbore, geophysical exploration, and hydrocarbon development technologies also provide better solutions to geothermal energy exploitation. Deep well drilling and hydrocarbon reservoir fracturing technologies can be used for create EGS (enhanced geothermal systems) reservoirs from deep hot dry rock. Therefore, oilfield companies have a unique advantage in oilfield geothermal energy exploitation.

The heat pump is the fastest growing and mature technology of geothermal energy direct utilization which has entered the commercial development stage. Heat pump is a heating air conditioning system with shallow geothermal energy as the low-temperature heat source, consisting of a water-source heat pump unit, a geothermal energy transfer system, and an end system. Compared with the efficiency of a heating system with a boiler (electricity, fuel), $50 \%$ of the energy can be saved by a heat pump with remarkable energy saving efficiency. As oilfield geothermal energy mainly consists of medium and low-temperature geothermal resources, the heat pump can be used to effectively exploit and utilize medium and low-temperature geothermal resources in produced water. Currently, heat pump pilot tests have been carried out in the Daqing Oilfield, Liaohe Oilfield and other oilfields, and achieved good economic benefits, suggesting the viability of possible large-scale development.

\subsubsection{Wide Geothermal Energy Utilization Market}

Geothermal resources have been frequently discovered during past hydrocarbon development, and oil companies have also tried to use geothermal resources. Huabei Oilfield, Liaohe Oilfield, Daqing Oilfield, Dagang Oilfield, Shengli Oilfield, etc. have tested the use of oilfield produced water for power generation, heating, bathing, flower farming, and heat-tracing gathering and transportation [20,21]. The implementation of these projects has involved technical personnel, technologies, and experience, the accumulation of which lays a solid foundation for further promotion and application.

Direct utilization of geothermal energy: geothermal energy can be utilized for heating, heat supply, and hot-water supply, with the advantages of simple operation and good economic benefit. Heating is needed 180 days a year in the oilfields in Northeastern China. A lot of heat energy is consumed in multipurpose stations, transfer stations, and other oil production units, and throughout the daily lives of oilfield workers and urban residents. Geothermal utilization can reduce the dependence on oil, gas, coal, and other conventional fossil fuels, not only saving energy but also having important market benefits [22].

Water gathering and transportation: Water gathering and transportation with oilfield produced water cannot only save considerable fresh water, but also makes full use of geothermal energy. Well-site heating furnaces are unnecessary when water gathering and transportation processes are implemented, saving considerable fuel and facilitating centralized control and automatic management.

Heat-tracing gathering and transportation: Oil (gas) is commonly used to heat water in oilfield heat-tracing gathering and transportation systems, which consume a large amount of oil and gas. The amount of wastewater produced in the oilfield with relatively high-temperatures can be used to replace heated water after purification treatment. In 2000, geothermal resources were utilized in the Jing'er multipurpose station of the Huabei Oilfield by reconstructing two high water-cut abandoned wells. The produced water of the 2 wells, $600 \mathrm{~m}^{3}$ a day at $100-110^{\circ} \mathrm{C}$, has been used as hot water for heating the oil and replaced water heated by a gas-fired or oil-fired boiler, saving $5 \mathrm{t}$ of oil and $3485 \mathrm{~m}^{3}$ of gas per day, and achieving significant economic benefits. 
Heat pump application: Oilfield produced water is usually a mixture of injected water and formation water, which is rich in oil and a variety of chemicals and particularly high in salinity due to long association with oil. Oilfield produced water also contains a lot of scale-forming ions, likely causing pipeline corrosion and blockage. Even after treatment, the oilfield produced water cannot be utilized directly as space heating and domestic hot water. According to the geothermal energy characteristics of oilfield produced water, "heat-utilizing without water consumption" technology can be used to extract the geothermal energy in oilfield produced water. The extracted geothermal energy can be utilized to provide heating and domestic hot water for oil production units and surrounding residents, which can effectively save coal, gas, oil, and other conventional resources, and protect the environment. At present, a jacket heater is often used in oilfield stations to heat incoming oil, which is characterized by high energy consumption, inconvenient management, etc. Based on years of heat pump study and application, the Liaohe Oilfield Water Supply Corporation (Panjin, China) has tried to develop a new process and explore the application of a water-source heat pump and gas engine driven heat pump in industrial production to replace the jacket heater used to heat oil. In 2014, a pilot project was implemented in the Xiaolongwan oil transportation pump station (Panjin, China). Currently, a heat-tracing pilot project with a gas engine driven heat pump is being tested in Shuwulian (Panjin, China), in which the separated gas in oil production is utilized as the driving force of the heat pump, and performs heat-tracing of incoming oil at a rate of $12 \mathrm{~m}^{3} / \mathrm{h}$ by extracting and utilizing the geothermal energy in the oilfield produced water. This project can save about $500 \mathrm{~m}^{3}$ of gas and $¥ 1500$ per day compared with the jacket heater. It is estimated that more than $¥ 12,000,000$ can be saved per year by utilizing gas engine driven heat pumps in a multipurpose station with a daily capacity of $7000 \mathrm{~m}^{3}$.

Geothermal power generation: Geothermal power generation is one of the most important ways of utilizing geothermal energy. High-temperature geothermal fluids should be first utilized for power generation. Geothermal power and thermal power are the same in principle, both converting steam heat energy into mechanical energy in the turbine and then driving the generator. The oilfield geothermal resource is mainly medium and low-temperature geothermal energy, and binary cycle generation is usually used for medium and low-temperature geothermal power generation. The oilfield geothermal power generation is only in the testing stage, with low efficiency, such as the helical screw expending power generator used in the Huabei oilfield. The most promising mode is the "one-well and one-station" scattered power generation, which can be taken to provide electricity for oil production in geothermal fields with relatively high geothermal resource potential.

To study the technical and economic feasibility of power generation with produced water in an oilfield, the Rocky Mountain Oilfield Research Center of the US DOE (The United States Department of Energy) carried out a power generation pilot project with low-temperature geothermal power associated with produced water beginning in $2006[23,24]$.

The researchers built an organic Rankine cycle power station of $250 \mathrm{~kW}$ in Block NPR-3 of the Naval reservoir in the Teapot Dome Oilfield in northern Wyoming (Casper, WY, USA) [25]. The power station uses produced water of $90.6-98.9^{\circ} \mathrm{C}$ on average to generate power, with a daily fluid production of 40,000 barrels/d. Generating power in binary cycle mode, and cooled by an air cooling system, its total power generation is $180 \mathrm{~kW}$ (net power generation of $132 \mathrm{~kW}$ ). The Ormat power unit was put into production in September 2008, and was decommissioned in 2014. Over its first 3.5 years of operation, this plant generated over $2210 \mathrm{MW} \cdot \mathrm{h}$ of electricity [26,27].

Another successful case is a new co-production project that just started operations in North Dakota, USA in late April 2016. With the support from the DOE Geothermal Technologies Office (GTO), researchers at the University of North Dakota (UND) have successfully generated geothermal power from $98{ }^{\circ} \mathrm{C}$ water that is pumped from water flood Enhanced Oil Recovery (EOR) supply wells in the Williston Sedimentary Basin in western North Dakota. This technology offsets the need for costly transmission construction and reduces energy costs at remote oil fields [28]. 
Therefore, strengthening exchanges and cooperation will speed up the development of China's medium and low-temperature geothermal power generation technology.

\subsection{Disadvantages in Oilfield Geothermal Energy Exploitation and Utilization}

\subsubsection{Immature Technologies in Geothermal Energy Exploitation and Utilization}

There is still a wide gap in overall geothermal resource exploitation and utilization between China and advanced countries, especially in oilfield reinjection, medium and low-temperature geothermal power generation, oilfield produced water treatment, heat transfer, and other technologies. There are only a few researchers engaged in geothermal exploitation and utilization in China's oil companies, the key technologies of geothermal energy exploitation and utilization have not yet been mastered, and most technologies are introduced from abroad. It is imperative to explore applicable new technologies and new ideas and develop new ways to exploit geothermal resources. On one hand, more effort should be put into scientific and technological research on deepening oilfield geothermal resource exploration and assessment, comprehensive exploitation and utilization of geothermal resources, economic assessment, geothermal water reinjection, and other technologies, to develop a complete set of geothermal exploitation and utilization technologies. On the other hand, it is necessary to strengthen exchange and cooperation, to establish an effective cooperation development system.

\subsubsection{Low Exploration and Assessment Levels of Geothermal Resources}

Relatively little assessment has been conducted on the geothermal potential of oilfields in China. Except for a few oilfields in eastern China, such as the Songliao Basin (Daqing, China) and the Bohai Bay Basin (Renqiu and Panjin, China), most basins and oilfields in China have not carried out a systematic and comprehensive exploration and assessment of geothermal resources, and there is no unified understanding of geothermal resources, which directly limits the exploration, exploitation, and utilization of geothermal resources.

\subsubsection{Lack of Overall Planning and Standards and Norms of Geothermal Energy Exploitation and Utilization}

Geothermal water is a valuable resource that combines heat, minerals, and water. Its optimum economic, resource, and environmental benefits can only be reached by comprehensive utilization, cascade utilization, and recycling utilization. The orientations of oilfield geothermal energy exploitation and utilization should be researched in order to achieve sustainable utilization, and a unified exploitation and utilization plan should be completed based on resource conditions. In addition, there are no standards and norms in geothermal resource exploration, resource assessment, hot-water reinjection, evaluation indexes of geothermal energy exploitation projects, etc. There are no functioning organizations and operation management institutions either, which will directly limit oilfield geothermal resource exploitation.

\subsubsection{Lack of Incentive Policies for Geothermal Energy Exploitation and Utilization}

The geothermal industry is a new industry with relatively low profits. Favorable industrial policies, finance and tax policies, technical research and development, and other aspects are necessary for geothermal enterprises to ultimately promote the vigorous development of the whole industry. There are no special fiscal subsidies or finance and tax policies for geothermal resource exploitation and utilization in China [29], as the national efforts in new energy development are concentrated on wind, solar, and biomass energy. The development of geothermal resources, despite their advantages, has not been given coordinative support policies in China. In order to promote the exploitation and utilization of geothermal resources, financial subsidies and tax breaks are necessary to reduce the operating costs of geothermal resource exploitation as much as possible. 


\subsubsection{Lack of Attention to Exploration and Exploitation Rights of Oilfield Geothermal Resource}

Oilfield geothermal energy, oil, and gas are symbiotic resources, but oil companies usually neglect geothermal energy exploration (exploitation) in the area with hydrocarbon lease rights. Geothermal energy is an energy mineral resource, and its exploration and exploitation should follow the "Mineral Resources Law of the People's Republic of China" [30], with corresponding supporting regulations and the need to be registered for lease rights. Therefore, oil companies should determine the legal process for geothermal resource exploration and exploitation rights and balance the relationship between hydrocarbon production and geothermal resource exploitation. For example, hydrocarbon layers and hydrothermal water layers are often superposed, and routine hydrocarbon production is likely to be interfered with by geothermal energy exploitation. Therefore, development modes should be researched to achieve coordinated exploitation and internal-external enterprise cooperation.

Generally, China has clear laws regarding mineral resources, and corresponding standards regarding emissions during the exploitation of geothermal fluids. In oilfield blocks being developed, we basically do not exploit geothermal resources lest the oilfield production be interfered with.

\section{Prospect of Oilfield Geothermal Energy Exploitation and Utilization}

Based on the above analysis of the advantages and disadvantages, there are two major applications in oilfield geothermal energy exploitation and utilization: the first is civilian applications, in which the rich oilfield hydrothermal geothermal resources can be utilized for geothermal heating. For example, a centralized system or small-scale decentralized system can be used to provide geothermal heating for oilfield residents and surrounding urban residents; this application would not only save gas and coal resources, but more importantly it would reduce $\mathrm{CO}_{2}$ emission and carbon particle diffusion, making great contributions towards haze control in northern China. It is worth noting that through several years of geothermal water reinjection testing in the Liaohe Oilfield and the Huabei Oilfield, a fairly mature reinjection process has been established, basically realizing full reinjection of the water after geothermal utilization, and significantly reducing the environmental pollution caused by the surface discharge. Industrial applications represent another major opportunity to utilize oilfield geothermal resources, including heat-tracing oil transportation, EOR with geothermal energy utilization, etc. With the technical progress in medium and low-temperature geothermal power generation and deep hot dry rock power generation, oilfield mid-deep geothermal resources can also be utilized for large-scale geothermal power generation to provide green electricity for hydrocarbon production, which will be the direction of the development of oilfield geothermal energy utilization in the next $5-10$ years.

\section{Conclusions}

(1) Petroliferous basins are rich in medium and low-temperature geothermal energy sources, and oil companies have made active attempts to exploit and use geothermal resources. Pilot applications have been carried out in the Huabei Oilfield, the Daqing Oilfield, and the Liaohe Oilfield, and have achieved good results and valuable experience. Currently, oilfield geothermal energy is mainly directly utilized for heat-tracing oil transportation and heating, and medium and low-temperature geothermal power generation pilot tests have only been carried out in the Huabei Oilfield. Sinopec is at the forefront of geothermal energy exploitation for residential heating, with the largest heating area in China. The Sinopec geothermal heating area by mid-deep formation $(200-3000 \mathrm{~m})$ is up to $40 \times 10^{6} \mathrm{~m}^{2}$, accounting for $40 \%$ of the total geothermal heating area in China, saving $1.2 \times 10^{6} \mathrm{t}$ of standard coal a year and reducing $3 \times 10^{6} \mathrm{t}$ of carbon dioxide emission a year.

(2) Oilfield geothermal energy exploitation and utilization has advantages regarding resources, personnel, technology, and a large number of abandoned wells available, which can greatly reduce the geothermal energy exploitation cost. In addition, due to high heat demand in oilfields, oilfield geothermal energy exploitation and utilization can not only effectively replace oil, gas, coal, and 
other fossil fuels, but also help to realize energy conservation, emission reduction, and green hydrocarbon exploitation.

(3) Currently, oilfield geothermal energy exploitation and utilization is characterized by immature exploitation and utilization technologies, low geothermal resource exploration and assessment levels, lack of overall planning and norms and standards, lack of incentive policies, lack of attention to exploration and exploitation rights, and other problems, which are the key factors that influence and restrict the large-scale rapid development of oilfield geothermal energy exploitation and utilization.

(4) There are two major applications in oilfield geothermal energy exploitation and utilization for the future: first is the civilian application, in which the rich oilfield hydrothermal geothermal resource is utilized for large-scale geothermal heating, making large contributions to haze control in northern China; second is the industrial application, including heat-tracing oil transportation, EOR with geothermal energy utilization, etc. The oilfield mid-deep geothermal resource can also be utilized for large-scale geothermal power generation to provide green electricity for hydrocarbon production.

Acknowledgments: This research is supported by PetroChina's project 2014A-4908. We thank senior engineer Xunan Huang from the research institute of petroleum exploration and development of PetroChina for his establishment of geothermal economic evaluation models.

Author Contributions: Shejiao Wang and Kewen Li conceived and designed the study. Jiahong Yan and Feng Li collected and compiled all the data and literature. Junwen Hu contributed the data analysis. Shejiao Wang wrote the paper. Kewen Li revised the manuscript.

Conflicts of Interest: The authors declare no conflict of interest.

\section{References}

1. Lin, W.; Liu, Z.; Wang, W.; Wang, G. The assessment of geothermal resources potential of China. Geol. China 2013, 40, 312-321.

2. Li, K.; Wang, L.; Mao, X.; Liu, C.; Lu, J. Evaluation and efficient development of geothermal resource associated with oilfield. Sci. Technol. Rev. 2012, 30, 32-41.

3. Xin, S.; Liang, H.; Hu, B.; Li, K. A $400 \mathrm{~kW}$ geothermal power generator using geo-produced fluids from Huabei Oilfield. Geotherm. Resour. Counc. Trans. 2012, 36, 219-223.

4. Liu, S.; Liu, T. Development and utilization of geothermal resources in oil regions. Contemp. Chem. Ind. 2014, 43, 2370-2373.

5. Yan, J.; Wang, S.; Zhao, Y. Geothermal energy saving "treasure" in oilfield. China Pet. 2007, 12, 54-56.

6. Wang, S.; Yan, J.; Li, M. Prospect of geothermal energy saving in petroleum industry. In National Symposium on Sustainable Development of Geothermal Industry; Chemical Industry Press: Beijing, China, 2005; pp. $232-238$.

7. Li, K. Feasibility study on utilizing mid-low temperature geothermal resource for power generation. Geotherm. Energy 2011, 1, 25-27.

8. Lei, Q.; Wang, H.; Wei, W.; Zhao, Q. Potential analysis on exploration of geothermal resources in oil and gas fields. Gas Ind. 2008, 28, 127-129.

9. Wang, J. Geothermics and Its Applications; Science Press: Beijing, China, 2015.

10. Zhang, L.; Yuan, J.; Liang, H.; Li, W. Energy from abandoned oil and gas reservoirs. In Proceedings of the 2008 SPE Asia Pacific Oil \& Gas Conference and Exhibition, Perth, Australia, 20-22 October 2008.

11. Li, K.; Zhang, L.; Ma, Q.; Liu, M.; Ma, J.; Dong, F. Low temperature geothermal resources at Huabei Oilfield, China. Geotherm. Resour. Counc. Trans. 2007, 31, 608-613.

12. Chen, M.; Deng, X.; Wang, J.; Waag, J. On the formation and accumulation of thermal water in North China Plain. Earth Sci. J. Wuhan College Geol. 1985, 10, 83-90.

13. Wang, J.; Huang, S.; Huang, G.; Wang, J. Geotemperature distribution and geothermal resources in the meso-cenozoic basins of North China. Acta Geol. Sin. 1983, 57, 304-316.

14. Liang, H.; Qian, X.; Xin, S.; Zhao, K.; Zhu, L. Assessment and development of geothermal resources in Jizhong Depression. New Energy 2010, 15, 63-68.

15. Wang, S.; Li, M.; Yan, J. Renewable Energy Path of Oil Company; Petroleum Industry Press: Beijing, China, 2013.

16. Muffler, P.; Cataldi, R. Methods for regional assessment of geothermal resources. Geothermics 1978, 7, 53-89. [CrossRef] 
17. Williams, C.F.; Reed, M.J.; Mariner, R.H. A Review of Methods Applied by the U.S. Geological Survey in the Assessment of Identified Geothermal Resources; U.S. Geological Survey Open-File Report 2008-1296; U.S. Geological Survey: Reston, VA, USA, 2008; p. 27.

18. $\mathrm{Bu}, \mathrm{X} . ; \mathrm{Ma}, \mathrm{W} . ; \mathrm{Li}, \mathrm{H}$. Geothermal energy production utilizing abandoned oil and gas wells. Renew. Energy 2012, 41, 80-85. [CrossRef]

19. Zhu, L.; Ning, Q. Exploitation and utilization of green energy to develop oilfield geothermal industry. Oil Forum 2005, 4, 19-25.

20. Zhong, X. Comprehensive utilization and energy saving prospect of geothermal resource in Daqing Oilfield. New Energy 2014, 2, 38-40.

21. Liu, J.; Yu, W.; Li, R. Discussion on technology for development and utilization of geothermal resources in oilfields. China Pet. Explor. 2013, 18, 68-73.

22. Zhou, Z.; Liu, S.; Liu, J. Study on the characteristics and development strategies of geothermal resources in China. J. Nat. Resour. 2015, 30, 1210-1219.

23. Karl, B.; Hebert, I.; Jesse, W. Electric power generation using geothermal fluid coproduced from oil and/or gas wells. Geotherm. Resour. Counc. Trans. 2009, 33, 671-672.

24. Johnson, L.A.; Walker, E.D. Oil production waste stream, a source of electrical power. In Proceedings of the Thirty-Fifth Workshop on Geothermal Reservoir Engineering, Stanford, CA, USA, 1-3 February 2010.

25. Anderson, T.C. The geologic and hydrologic setting of NPR-3 (Teapot Dome) Wyoming and its EGS geothermal potential. Geotherm. Resour. Counc. Trans. 2010, 34, 285-289.

26. Nordquist, J.; Johnson, L. Production of power from the co-produced water of oil wells, 3.5 years of operation. Geotherm. Resour. Counc. Trans. 2012, 36, 207-210.

27. Wight, N.M.; Bennett, N.S. Geothermal energy from abandoned oil and gas wells using water in combination with a closed wellbore. Appl. Therm. Eng. 2015, 89, 908-915. [CrossRef]

28. Gosnold, W. The UND-CLR geothermal power plant. In Proceedings of the 8th International Conference, Power Plays: Geothermal Energy in Oil and Gas Fields, Dallas, TX, USA, 25-26 April 2016.

29. Luo, H. Exploitation and utilization of geothermal resources and industry development in China. Urban Resour. Environ. 2015, 52, 197-199.

30. Mineral Resources Law of the People's Republic of China; Law Press: Beijing, China, 1986.

(C) 2016 by the authors; licensee MDPI, Basel, Switzerland. This article is an open access article distributed under the terms and conditions of the Creative Commons Attribution (CC-BY) license (http://creativecommons.org/licenses/by/4.0/). 